\title{
Least-Cost Path and Accessibility Analysis of a High Speed Railway Corridor: Victorville, CA to Las Vegas, NV
}

\author{
Max David McDonald $₫$, Fritz Connor Kessler (1) \\ College of Earth and Mineral Sciences, Penn State University, State College, USA \\ Email: maxmcdonald014@gmail.com
}

How to cite this paper: McDonald, M.D. and Kessler, F.C. (2022) Least-Cost Path and Accessibility Analysis of a High Speed Railway Corridor: Victorville, CA to Las Vegas, NV. Journal of Geographic Information System, 14, 40-60.

https://doi.org/10.4236/jgis.2022.141003

Received: January 13, 2022

Accepted: February 21, 2022

Published: February 24, 2022

Copyright $\odot 2022$ by author(s) and Scientific Research Publishing Inc. This work is licensed under the Creative Commons Attribution International License (CC BY 4.0).

http://creativecommons.org/licenses/by/4.0/

\begin{abstract}
Geospatial technology is a useful tool when identifying land corridors for transportation networks. The primary transit corridor between Los Angeles, CA and Las Vegas, NV is Interstate-15, approximately a four-hour automobile trip without traffic. Virgin Trains USA LLC proposes an alternative means of travel by constructing a high-speed railway along Interstate-15 connecting Las Vegas and Victorville, CA. This study uses least-cost path analysis to propose an optimized alternative corridor for Virgin Trains' proposed high-speed railway through a system facilitated road and rail accessibility analysis. Previous research using least-cost path and accessibility methodologies evaluated the results of proposed high-speed railway corridors and the system facilitated accessibility changes by visually inspecting deviations from a planned corridor using single or multiple cost criteria as inputs for a weighted cost surface. However, robust analyses of previous least-cost path studies' corridors are lacking. This proof-in-concept study proposes a less costly corridor through least-cost path analysis and measures the social impact on the stakeholders of a high-speed railway transportation system through system facilitated accessibility. This study's proposed alternative corridor is 31\% shorter than Virgin Trains' planned corridor and system facilitated accessibility to Las Vegas, NV is increased in $99.74 \%$ of Los Angeles County's census tracts. These results support this study's position that geospatial technology can support transportation planning in a comprehensive method that considers the transportation corridor and benefits its stakeholders.
\end{abstract}

\section{Keywords}

Analytical Hierarchy Process, GIS, High-Speed Railway, Least-Cost Path Analysis, Route Analysis 


\section{Introduction}

Virgin Trains USA (VT) has begun the process of securing U.S. Federal Railroad Administration (FRA) approval to construct its newest high-speed railway (HSR) between Las Vegas, NV and Victorville, CA. The VT HSR corridor will be constructed alongside of Interstate-15 (I-15) and will travel 90 minutes, non-stop from Victorville to Las Vegas Boulevard across from the South Premium Outlets [1], approximately three miles southwest of McCarran International Airport. While no estimate of passenger ticket prices has been established, the project will cost approximately 4.8 billion dollars (USD) and is primarily being funded via the California Infrastructure and Economic Development Bank [2] and Fortress Investment Group. If a privatized entity or local/federal government can wade through the complex decision matrices that exist in transportation planning and propose a corridor between two places, it is still unlikely that the corridor will be established due to financial feasibility or other socio-economic factors. For the corridors that do become a reality, little literature explores the analysis of the path chosen for those corridors and how it impacts its users in a social or economic sense. This study recognizes that HSR planning should give attention to all relative factors as necessary before construction, however the extent of socio-economic, technological, \& environmental factors required for a robust and successful HSR is too large to address for the purposes of this study.

VT does not publicly address its purpose or means and methods for developing its proposed HSR corridor. Whether VT aims to reduce traffic congestion throughout I-15 or provide more access between Los Angeles (LA) County and Las Vegas is not clear. This incites the following questions: how would VT justify a multibillion dollar transportation project? Furthermore, has VT robustly designed the selected corridor and measured its accessibility impact to the users of the transportation system? With the impacts to the stakeholders and users of the VT HSR project in mind, this paper provides an optimized alternative least-cost path (LCP) HSR corridor to contrast against the VT planned corridor and determine which is more optimal. Following the LCP analysis, this study is extended to contrast the proposed and planned corridors by rapidly assessing the social impact to the users through a system facilitated accessibility index. Accomplishing this will provide a robust analysis of VT's planned corridor and establish a foundation for predicting a good return on investment (ROI) for the stakeholders, furthermore, assisting in the socio-economic justification for such a transportation project.

A LCP is a common method for identifying optimized alternatives when siting the location of a corridor (e.g., linear engineering structure projects like a new roadway or highway, pipeline, telecommunication network, urban greenway, and HSR). Cost path is an analysis tool within a geographic information system (GIS) that determines the least costly route between two locations (where "cost" could be time, distance, or another metric). A LCP is created in GIS using a raster cost-surface that is defined by influencing cost criteria relevant to the objec- 
tives of the project. Research commonly evaluates a LCP alternative by comparing its accumulated minimized costs against the planned or existing corridor(s) (i.e., determining which corridor is least costly). Previous studies involving LCP analysis have assessed the results via visual comparisons that show alternative corridors, quantified a decrease in the number of vertex points, thus having less length (therefore predicting lower construction costs) or compared the cost criteria and the overall accumulated costs to prove which corridor is least-costly.

In transportation corridor planning and analysis, building and utilizing a LCP as an optimized alternative route should not solely be selected by visualizing deviations from a planned corridor according to, for example, a reduction in overall length or accumulated costs. Instead, the appropriateness of a LCP corridor should be valued not only by its accumulated cost criteria, but also by the impact of that corridor on the user(s) or stakeholders of the transportation network. Existing literature has not focused on assessing the LCP according to the stakeholder. To address this shortcoming, this study has two goals, the process of which is summarized in Figure 1. First, based on previous research, this study uses LCP methods in ESRI's ArcMap to site an alternative HSR corridor which will then be compared to VT's planned HSR route. Second, to assess this comparison, this study uses ArcMap to evaluate the success of the LCP alternative corridor (against the VT planned HSR route) by measuring the overall impact on stakeholder accessibility from LA County census tracts to Las Vegas. By measuring the impact on LA County accessibility to Las Vegas between the planned and proposed corridors, this study will have provided a means to assist in justifying HSR transportation corridors.

This study's proposed LCP alternative route is developed through multi-criteria evaluation (MCE). Researchers have frequently used MCE techniques to propose solutions for linear engineering structures. Choosing an appropriate MCE derived model involves different techniques that rate multiple solutions in complex problems where each solution has varying criteria [3]. One specific MCE technique, analytical hierarchy process (AHP), is chosen for this study to construct an optimized alternative LCP-HSR corridor. AHP allows decision makers to arrive at a scale of hierarchy drawn from a set of alternatives [4]. AHP has been applied to

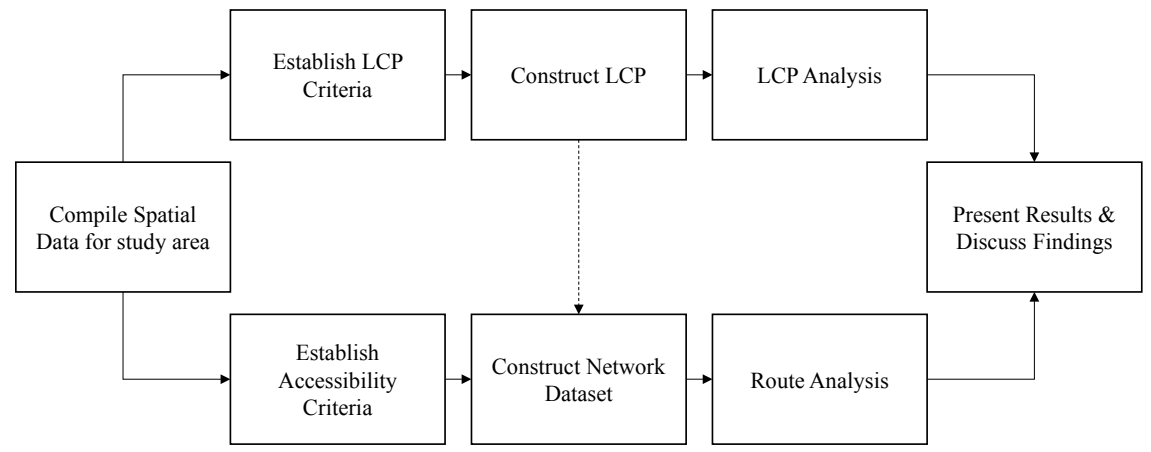

Figure 1. The analytical workflow for proposing a LCP alternative HSR corridor and contrasting it with the VT planned HSR corridor. 
site selection analysis (see [5] [6] \& [7]), routing of HSRs [8] and other linear engineering structures (see [9] \& [10]), as well as the modeling of habitat corridors (see [11] \& [12]). AHP involves a series of calculations that begins with the construction of a pairwise comparison matrix (PCM). A PCM compares two objects (decision criteria and decision alternatives) at once, rather than decision makers comparing several objects at once, and results in an aggregate best-choice hierarchy, relating to the best perceived criteria [13]. With AHP, cost does not have to refer to monetary units. Instead, cost can be a single expense or an accumulation of multiple expenses. With this study's three cost criteria, the proposed LCP aims to minimize the LCP accumulated costs compared to VT's planned corridor. The cost criteria are broken down into data-driven sub-categories and weighted through AHP to produce the accumulated cost surface required for LCP calculation in ArcMap (Figure 2).

Not only can a GIS and AHP be combined in this spatial problem for the study of an optimized alternative LCP corridor, but GIS software can also further support the comparison of the two corridors' results by depicting their differences in their impact to accessibility between two places. Existing literature does not provide a formal established method of evaluating accessibility, and its definition varies depending on its context of use. This study defines accessibility as an entity's effort expended to reach a destination within a road and rail transportation network, henceforth referred to as system facilitated accessibility (SFA). For this study, the authors survey existing literature to build a foundational definition of accessibility, which is then used to create a SFA index to evaluate the present and future states of LA County's access to Las Vegas, measured as a function of generalized costs within a transportation network.

\section{Literature}

\subsection{HSR Corridor Planning}

Broadly speaking, transportation planning involves network design, line planning, timetabling, rolling stock planning, and crew rostering and scheduling [14].

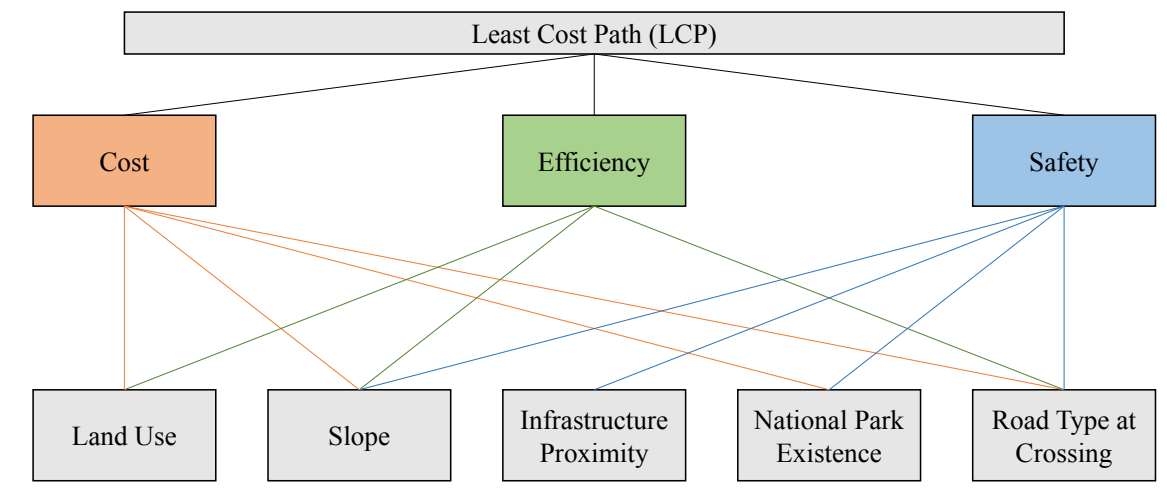

Figure 2. LCP cost criteria and the data-represented sub-criteria for the construction of the proposed LCP and for contrasting against VT's planned corridor. 
Furthermore, specific planning problems as applied to the operation and maintenance of a HSR is provided in [15] and include strategic problems, tactical problems, operational problems, and other aspects. Literature investigating the sequence of planning problems provided by [14] has yielded many analyses that focus on network design and rolling stock planning (see [15] \& [16]), as well as timetabling (see [17] [18] \& [19]). The issue of corridor selection/line planning, though not robustly analyzed in literature, is the focus of this study.

One reason that corridor selection is not well studied is due to the focus on HSR corridor prioritization. Corridor prioritization is the process of selecting which two places will be connected via HSR. Corridor prioritization decision makers attempt to justify why two places deserve a HSR corridor over other origin/destination pairs. In the United States, for example, the American Recovery and Reinvestment Act (ARRA) allocated eight billion USD to states for intercity rail projects for high-speed, intercity services [20]. The ARRA specifically addressed the need for new transportation projects to adhere to several strategic goals, such as building a foundation for economic competitiveness [20]. Moreover, the ARRA references President Obama's memorandum regarding responsible spending of recovery act funds and would select transportation projects based on a merit approach, only granting funds to projects that maximize public benefits and mitigate risks [20]. In Europe, initial HSR corridors were not prioritized, demand forecasting was the primary focus, and little research has been conducted on corridor optimization (e.g., LCP or other corridor planning methods) [21]. A specific example of this fact was a study conducted on the City of Osijek in Croatia in 2021. The city's primary railroad contributed to sustainable urban growth and suggested future demand forecasting of HSR corridors focus on their potential to contribute to urban development and socio-economic growth [22]. The Croatia study did not consider or propose whether a different location of the corridor would produce more benefits to sustainable urban growth and development. In China, HSR construction projects are subject to a system parameter evaluation that include project contents, demand forecasting, construction and maintenance costs, economic benefits, environmental impacts, capital estimation and fund raising, financial sensitivity analysis, and risk analysis to determine the new corridors that will join their existing HSR network [23]. Supplemental evaluations of China's corridor prioritization process did not focus on corridor optimization in terms of line planning [23]. These studies agreed that evaluation systems for Europe and the United States look to demand forecasting when choosing two termini for a new HSR corridor [21] \& [23]. Studies concluded the lack of quality in existing demand forecasting methods and proposed a ranking model approach for the United States and Spain that heavily relies on a new HSR network planning process to identify its main targets and priorities before choosing which locations a corridor will connect [21].

\subsection{Least-Cost Path Analysis}

Despite the evidence that local and federal governments avoid corridor selec- 
tion/line planning, previous research has been conducted on the subject using LCP analysis. The existing literature provides a solid foundation for understanding and implementing LCP analysis for the purposes of this study. For example, ground-based drug trafficking corridors have been predicted using physical, socio-demographic, and drug violence cost criteria to construct a cost surface [24]. Specifically, alternative corridors were overlaid to show deviation from known historical corridors [24]. LCPs have been employed for power line corridor selection using landscape, human health, and nature factors as cost criteria [10]. Weighted topography factors such as restricted areas, ridges, slopes, rivers, streams, industrial areas, and roads have been cost criteria for a utility pipeline corridor [25]. A line-based cartographic simplification process was utilized on a new pipeline to illustrate a decrease in the number of vertices [25]. A pairwise comparison matrix of eight cost criteria was applied to a LCP to decrease generalized costs for an HSR project [8]. Corridors were compared by the total costs of each pairwise comparison criteria (land cover, slope, soil, and river crossings) [8]. Finally, overall corridor distances were compared among multiple alternatives through different LCP construction methodologies [26].

These studies have successfully shown that use of a LCP has reduced costs for their linear engineering structures and transportation networks. However, the methodology for supporting their alternative corridors ends with evaluating the cost criteria, a common approach that is used in transportation and allied literature (i.e., [27] [28] \& [29]). Studies that have conducted an accessibility analysis on planned or real HSR corridors using LCP alternatives are seemingly absent. Those studies that do exist do not go beyond the methods previously seen in other transportation networks or linear engineering structures. An example of this, mentioned earlier, compared overall alternative corridor lengths with the amount of unsuitable crossings of topographic cost criteria to optimize their alternative corridor in Turkey [8]. Another LCP-HSR example was based within Texas where a LCP was utilized to propose an HSR corridor between the San Antonio and Austin airports and only justified the optimized alternative via the total length of the LCP, estimated HSR travel time, total track area, and estimated construction costs [30]. The authors even concluded that spatial decision support systems (e.g., a LCP derived in GIS) should constantly be tested and developed for the rational investment decisions [30]. The authors further add that future uses of the system should be modified to address the perceptions held by stakeholders [30].

\subsection{Accessibility}

Accessibility of persons or places has widely been studied in previous research. For instance, accessibility has been described as the ease (or difficulty) that opportunities (e.g., employment) or services can be reached from a location [31]. Accessibility has also been described as the travel impedance in terms of travel distance or travel time between two locations [32], but also has been addressed 
in terms of health care services as the dimensions of availability, accessibility, accommodation, affordability, and acceptability [33]. Building on the concept that accessibility is not just a function of distance or travel time, six different concepts of accessibility were identified and examined: 1) system accessibility, 2) system facilitated accessibility (SFA), 3) integral accessibility, 4) space-time geography (see [34]), 5) utility theory, and 6) relative accessibility [35]. Relative accessibility is based on comparing access between modes or types of users [36]. For example, if the consumer has a choice between using a personal vehicle and using public transportation in travelling to a destination, the choice is made as a function of monetary cost, time, convenience, and safety [36]. This study uses SFA to determine which corridor (the proposed LCP or the planned VT HSR corridors) makes LA County more accessible to Las Vegas. This strategy is similar to the approach where the cost to travel through a transit system considers distance and monetary components of any journey along a network as a unified value [37]. The key benefit of this method is the ability to evaluate new transportation infrastructure projects by rapidly appraising the effects on accessibility [37]. Application of this method to the greater London area shows that networks of different transportation modes can be analyzed over large spatial scales and reveals considerable spatial variability in transport costs and accessibility [37].

\section{Methodology}

\subsection{Least Cost Path}

To develop a LCP, AHP uses a PCM to produce criteria weights for the ArcMap weighted overlay and cost surface tools. The outputs produce an accumulated raster cost surface required for LCP creation via the ArcMap cost path tool. Cost criteria are ranked as important or unimportant when compared against the other criteria and were assigned based on the authors' subjective perception of their importance. For example, a value of 1.0 means the two criteria being compared are equal in importance. Values greater than 1.0 represent a higher level of importance while values less than 1.0 suggest a level of lower importance. For this study, the sub-criteria used to develop the criteria weights include land cover, slope, infrastructure proximity, national park existence, and road type at rail crossing (Figure 2). These criteria are weighted through AHP in a PCM as shown in Table 1. A 1 - 3 scale ranking system is used in this study to reduce the consistency ratio (CR) because the hierarchical evaluations of criteria weights here were attributed to the authors' common knowledge and by examining the relevant literature, representing a proof-of-concept study. PCMs are usually assigned and produced by multiple experts/stakeholders.

Besides producing criteria weights for the ArcMap weighted overlay and cost surface tools, a PCM also establishes a CR for the ranking of criteria as a hierarchy. The AHP theory of measurement aims for a consistent ranking of criteria measured by the CR [4]. The CR measures the rankings in the PCM to determine how random the criteria weights are. A CR larger than 0.10 would indicate a need to 
Table 1. LCP cost criteria and the data-represented sub-criteria for the construction of the proposed LCP and for contrasting against VT's planned corridor.

\begin{tabular}{ccccccc}
\hline & $\begin{array}{c}\text { Infrastructure } \\
\text { Proximity }\end{array}$ & $\begin{array}{c}\text { National } \\
\text { Parks }\end{array}$ & Slope & $\begin{array}{r}\text { Road } \\
\text { Type }\end{array}$ & $\begin{array}{c}\text { Land } \\
\text { Use }\end{array}$ & $\begin{array}{c}\text { Criteria } \\
\text { Weights }\end{array}$ \\
\hline Infrastructure Proximity & 1.0000 & 1.1000 & 1.0000 & 1.6670 & 1.2670 & 0.2 \\
National Parks & 1.4670 & 1.0000 & 1.0000 & 1.7000 & 1.4000 & 0.21 \\
Slope & 1.3000 & 1.3000 & 1.0000 & 1.9000 & 1.5000 & 0.23 \\
Road Type & 1.0670 & 0.8670 & 0.7670 & 1.0000 & 1.0670 & 0.16 \\
Land Use & 1.2000 & 1.1000 & 0.9670 & 1.6670 & 1.0000 & 0.2 \\
Sum & 6.0340 & 5.3670 & 4.7340 & 7.9340 & 6.2340 & \\
CR & 0.2370 & & & & & \\
\hline
\end{tabular}

re-examine the PCM rankings, but sometimes a CR of 0.20 is acceptable depending on the analytical problem [4]. The creation of a PCM to produce criteria weights, and a CR which evaluates them, is not as straightforward as the single matrix in Table 1. AHP is a multi-step, mathematical process that produces the criteria weights before the CR is produced at the end to evaluate the MCE method. Furthermore, the PCM is usually filled out with a larger scale of rankings (1 - 9) than those used in Table 1 (i.e., uses 1 to 3). In this study, criteria weights are produced via multiple PCMs, each favouring a particular criterion, then averaged together for a proof-of-concept PCM that would normally have been determined by experts/stakeholders for an LCP-HSR proposal.

The shapefiles or raster data selected for the LCP cost surface are organized by their relationship to the sub-criteria of the LCP. For example, each sub-criterion relationship is reclassified in ArcMap as its own individual cost surface with its individual AHP derived weight. Then, the cost surfaces are inputted into the ArcMap weighted overlay tool to create an accumulated cost surface with the averaged PCM weights (Table 1).

\subsection{System Facilitated Accessibility}

In this study, the SFA analysis contrasts the accessibility from LA County census tracts to Las Vegas between the proposed LCP alternative and VT planned HSR corridors. Each LA County census tract is assigned a SFA index to rank their overall accessibility for the scenarios in Table 2.

The first scenario establishes a baseline SFA index to determine the current level of accessibility from LA County to Las Vegas where the only option is to drive. The second and third scenarios establish the SFA indices to evaluate which corridor offers better access to persons in LA County. The effort of reaching Las Vegas is a function of line segment length through a transit network (road and railway distances), travel costs (gasoline usage per mile for cars and railway ticket prices), and time, which is determined by the speed limits on roads and highways, as well as the top speed local railways (e.g., the City Metro) or HSRs can reach legally. 
Table 2. SFA index scenarios.

\begin{tabular}{cl}
\hline Scenario & \multicolumn{1}{c}{ Person's Accessibility to Las Vegas } \\
\hline 1 & Drive form a LA County census tract. \\
2 & $\begin{array}{l}\text { Drive and/or utilize the existing train network form a LA County } \\
\text { census tract with the inclusion of the LCP alternative corridor. }\end{array}$ \\
3 & $\begin{array}{l}\text { Drive and/or utilize the existing train network from a LA County } \\
\text { census tract with the inclusion of VT's planned HSR corridor. }\end{array}$ \\
\hline
\end{tabular}

This study uses four steps to measure the accessibility of a group of geographical zones to a location [37]. The process is briefly outlined below [37]:

1) Define geographical zones.

2) Build transportation networks.

3) Create a matrix of generalized costs within the transportation networks.

4) Use computed generalized costs to determine accessibility to destination of interest.

Generalized cost equations are defined by transportation modes. For private modes of transportation (e.g., a personal car), the equation is as follows [37]:

$$
C_{P V T}=\left(V_{W K} * A\right)+T+D *[(V O C / o c c) * V O T]+[(P C / o c c) * V O T]
$$

And for public modes of transportation (e.g., a bus or HSR), the equation is represented as [37]:

$$
C_{P U B}=\left(V_{W K} * A\right)+\left(V_{W T} * W\right)+T+(F / V O T)+1
$$

In Equations (1) and (2), $V_{W K}$ is the disincentive weight for walking to an access point in a transportation network, $A$ is the amount of time it takes to reach the access point, $V_{W T}$ is the disincentive weight for waiting at an access point, $W$ is the total amount of time waited for the journey to the destination, $T$ is the total time spent on the journey, $F$ is the fare or dollar amount spent on the journey, VOT is the value of time coefficient, $D$ is the distance in kilometers, $V O C$ is the vehicle operating costs per kilometer, $P C$ is parking or other costs, and $o c c$ is the number of vehicle occupants.

This study uses modified monetary cost, distance, and time equation inspired in [37]. The SFA analysis in this study only focuses on monetary costs incurred, time spent on journeys, and distances travelled alone. Thus, wait times at access points were ignored to create a simpler access model. Value of time (VOT) was higher for $C_{P V T}$ costs (two, rather than one) as people in a hurry are assumed to take travel matters into their own hands, rather than rely on public transportation modes. Vehicle occupancy uses a fix setting of one which is this study's approach to model the SFA at an individual level, as well as the fact that commuter carpooling in the U.S. has decreased from $19.7 \%$ in 1980 to $9.4 \%$ in 2013 [38]. Disincentives for transferring between stations was not factored into this study's equations, as transferring between the Southwest Chief station and VT's Victorville station is inconvenient, but necessary. 
Parking, or other costs $(P C)$ (e.g., tolls) was ignored due to the unavailability of public data. Therefore, the modified equation utilized here to measure SFA by each of LA County's census tracts to Las Vegas is represented for private $\left(C_{P V T}\right)$ and $\operatorname{HSR}\left(C_{H S R}\right)$ as follows:

$$
\begin{gathered}
C_{P V T}=D+T *(V O C * V O T) \\
C_{H S R}=D+T *(F * V O T)
\end{gathered}
$$

where $D$ is the total miles spent on the road or railway network, $T$ is the total hours spent on the trip, VOC remains as vehicle operating costs as well as VOT remaining as a value of time, and $F$ remains as the fare cost incurred when travelling on a railway or HSR. VOT is set at a value of one for $C_{H S R}$ and two for $C_{P V T}$ since people who are in a hurry or value their time more may not rely on public transportation to get them where they need to go.

ESRI's ArcMap was used for the SFA analysis due to its ability to create a robust transportation network database. In the project's study area, spatial data representing the existing road and railway network are used as network dataset inputs [39]. Station addresses and origin/destination points were also inputted. The station coordinates were derived from address geocoding on field tables containing each station's address listed on Google. Station entrances are point feature classes created with the ArcMap near tool. These entrances represent points nearest to the station feature classes on roads or highways. For connectivity reasons underlying network dataset creation, it is crucial that the station entrances lie on the road and highway network as the stations themselves fall on the railway network. Within the network dataset, transfer street and transfer station vectors were manually created to serve the purpose of transferring between different transportation nodes when moving through the network. The 2344 census track centroids are snapped to the transportation network via the ArcMap near tool and serve as the various origin points while the Clark County, NV centroid (which falls inside of Las Vegas) satisfies the only destination point for every route calculated. ArcMap refers to these points as "Stops" in the context of network datasets.

Roadway and railway network components require unique attribute fields to accumulate cost impedances when ArcMap is traversing the network dataset and calculating a route. Without at least one method of measuring impedances, the network dataset is unable to solve a route between an origin and the destination. To complete Equations (3) \& (4), the roadways and railways of this study's network dataset contain multiple fields for calculating cost impedances (Table 3).

Each origin/destination pair is inputted into a Python script [40] that splits and merges each census tract origin to the Las Vegas destination, stores them in their own file geodatabase, and calls the new output a unique name (“Stop_0001", “Stop_0002", etc.). The "ID” field in each new Stops feature class contains the corresponding "ID" field for each origin census tract. This is useful later in the analysis when combing the SFA index from the route with the original 
Table 3. Attributes of the polylines in the network dataset.

\begin{tabular}{|c|c|c|c|c|c|}
\hline Name & Usage & Units & Railways Field Name & Roadways Field Name & Equation \\
\hline Fare & Cost & Monetary & “Cost" & $\mathrm{N} / \mathrm{A}$ & ${ }^{\star}$ Fixed Price ${ }^{\star}$ \\
\hline Domestic Price & Cost & Monetary & $\mathrm{N} / \mathrm{A}$ & "Domestic_Price" & "Shape_Length_Miles" * \$3.45 \\
\hline Feet & Cost & Feet & "Shape_Length" & "Shape_Length" & ${ }^{\star}$ Shape_Length already in feet units* \\
\hline Miles & Cost & Miles & "Length_Miles" & "Shape_Length_Miles" & “Shape_Length"/1000 \\
\hline Hours & Cost & Hours & "Hours" & "Hours" & $\begin{array}{c}\text { "Length_Miles" or } \\
\text { "Shape_Length_Miles"/“Speed" }\end{array}$ \\
\hline Minutes & Cost & Minutes & "Minutes" & "Minutes" & “Hours" * 60 \\
\hline
\end{tabular}

census tract polygon feature class. As mentioned earlier, there are 2344 census tract polygons within the conterminous LA County. Therefore, after formatting the origin/destination stops into pairs with their individual "ID" fields, one could automate the process of solving each route with Python and save and view the results.

To view and compare the SFA results, the Python script is executed three times for the three scenarios described in Table 2. Within the network dataset parameters, a restriction attribute is created to simulate traversing through the network dataset without the option to enter a railway. This restriction ("DriveOnly") makes the ArcMap network analyst solve tool unable to consider the railway element of the network dataset. Thus, one automated script is conducted with the "DriveOnly" restriction turned on, and two with this restriction turned off. To turn "DriveOnly" on within the Python script, the ArcPy "make route layer" network analyst class would have to include "DriveOnly" where nothing is included in the environment setting parameter "restrictions".

Following completion of the Python script for each modeling scenario, ArcMap merge tool combines the three sets of 2344 routes, respectively. Access index fields were added to each group of merged routes created with and without the "DriveOnly" restriction turned on ("DriveAccessIndex" for "DriveOnly" restrictions, and "TrainAccessIndex_VT" or "TrainAccessIndex_LCP” without). These fields were calculated with Equations (3) and (4), respectively, to receive the SFA indices. Following the field calculations, the three newly merged route feature classes are table joined to the census tract feature class through the "ID" field relationship. Finally, once the census tract feature class contained the appropriate fields, the percent change in SFA is calculated between the two SFA fields for scenarios 2 and 3. Two new fields in the census tract feature class are added and named "Change" and "PercentChange", and calculated by Equations (5) and (6). A third change field ("PercentChange_VT_LCP") is also added, calculated by Equation (7), to determine which census tracts benefit from which corridor. Negative values resulting from Equation (7) benefit more from VT's planned corridor, values of 0 represent an equal level of SFA, and positive values experience more benefit from the LCP alternative corridor. 


$$
\begin{gathered}
{[\text { Change }]=[\text { DriveAccessIndex }]-[\text { TrainAccessIndex }]} \\
{[\text { PercentChange }]=[\text { Change }] /[\text { DriveAccessIndex }]} \\
{[\text { PercentChange_VT_LCP }]=([\text { TrainAccessIndex _VT }]} \\
-[\text { TrainAccessIndex_LCP }]) /[\text { TrainAccessIndex_VT }]
\end{gathered}
$$

\section{Results}

The resulting AHP-optimized, LCP alternative corridor and VT's planned HSR corridor are represented in Figure 3 over the accumulated cost surface raster. Green raster cells represent the lowest cost cells, while yellow represents the medium costs, and red, the highest cost cells.

The ArcMap extract by mask tool is utilized to uncover quantifiable data to compare and contrast the proposed LCP alternative and VT's planned HSR corridors. After converting each corridor's raster LCP outputs to polylines, the extract by mask tool takes the cost categories of raster cells under each corridor, and the results are displayed in Figure 4. Figure 4 shows that the proposed LCP alternative corridor traverses considerably more low cost cells (6847) than the VT planned HSR corridor (135) at roughly a 51:1 ratio.

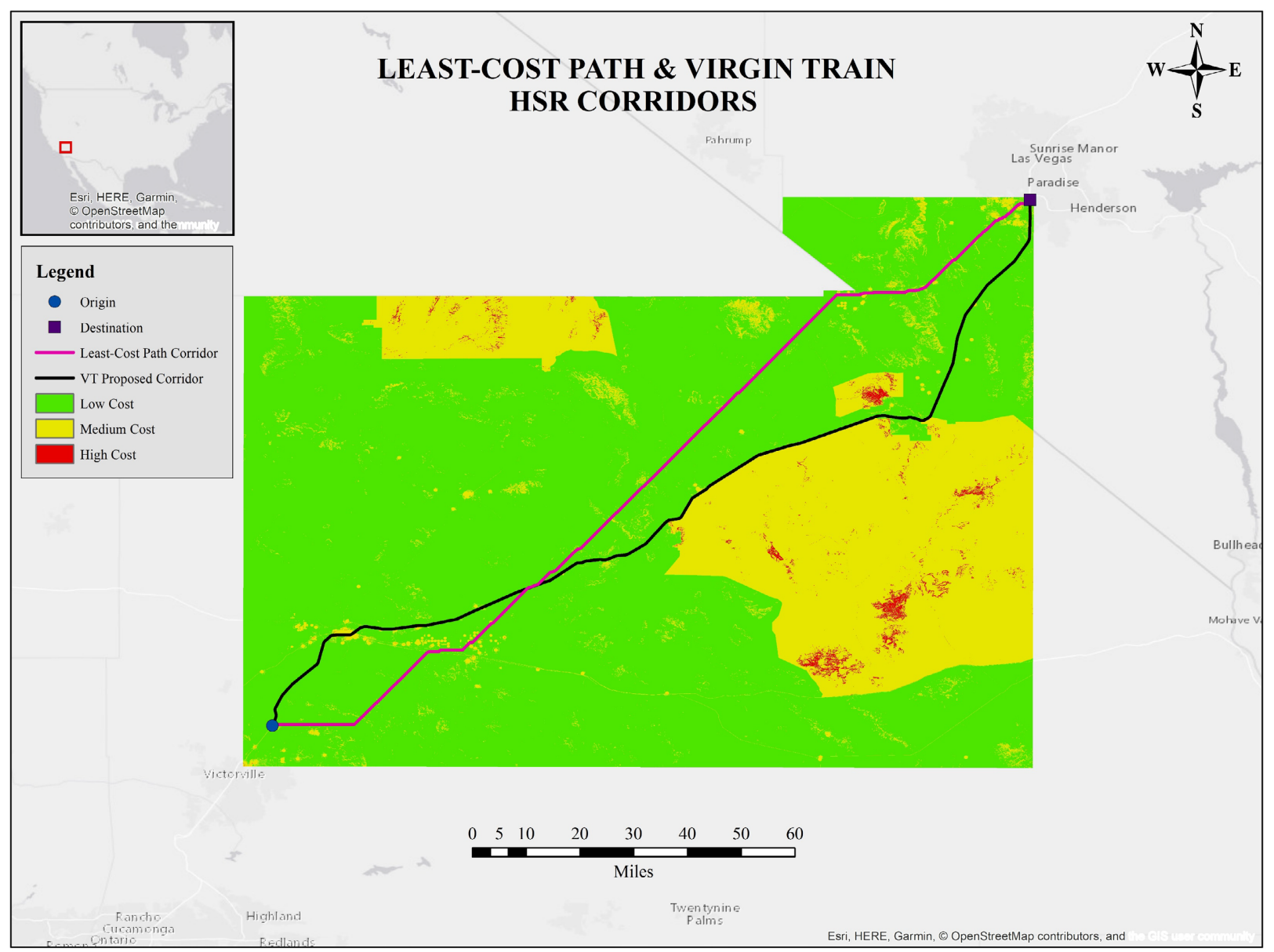

Figure 3. The LCP contrasted against the proposed HSR corridor by VT. 


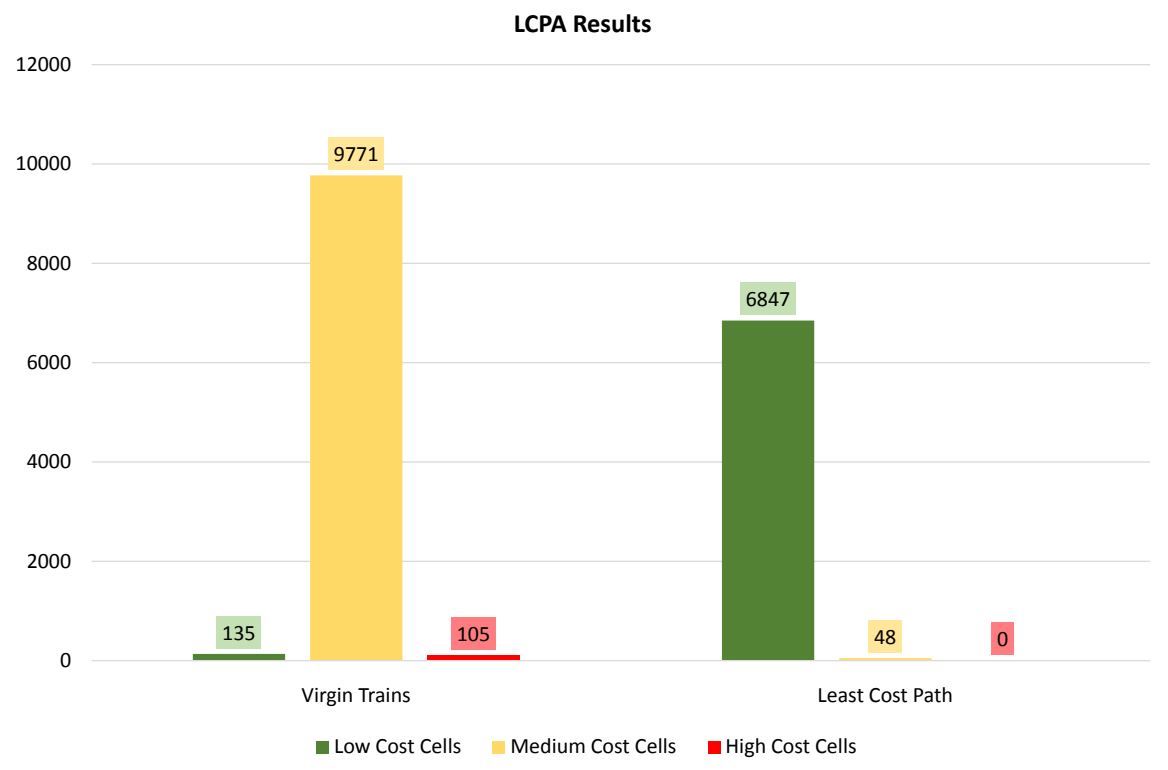

Figure 4. A bar graph contrasting overall lengths and costs of the two corridors.

The VT corridor utilizes 10,011 cells to reach the destination in Las Vegas. This is 3116 (31\%) more cells than the more direct LCP alternative corridor, which accumulates to 6895 cells. It is discernable that the LCP alternative corridor traverses a significantly lower number of medium cost cells (48) than the VT planned corridor (9771) at roughly a 204:1 ratio. The LCP alternative corridor records no high cost cells as opposed to VT corridor which accumulates 105 high cost cells. This indicates that the LCP alternative corridor is less costly when contrasted to the VT HSR corridor.

The LCP alternative corridor in this study is overall less costly than VT's planned corridor. The LCP analysis speaks to GIS as a useful tool for evaluating the cost, safety, and efficiency for HSRs in this context. This study recognizes that there may or may not exist political, socioeconomic, or other environmental factors that determine where exactly VT is seeking and/or allowed to build their HSR, however, the employment of LCP analysis with appropriate/accurate data and stakeholder/expert influence, can discern a better corridor during the planning and design phases of HSR construction.

This LCP analysis has four primary limitations:

1) This proof-in-concept exercise of AHP did not include experts or stakeholders to help determine the criteria weights. For the criteria influencing the LCP to encompass the full scope of such a project, experts and stakeholders involved with the HSR must be consulted.

2) In spite of their absence, with the criteria chosen to influence the LCP through AHP-determined criteria weights, this study calculated a $23.7 \%$ consistency ratio based on their pairwise comparison ratings, which is not acceptable according to standards [4] and leaves room for improvement within the AHP model.

3) The extract by mask tool uncovers that the LCP corridor passes over a more 
higher slope cells than VT's planned corridor (Figure 5). This indicates a major weakness in the LCP as areas with high slope are not desirable for HSR construction. The elevation data is from the USGS' National Map and at a $1 / 3$ arc-second resolution, therefore this weakness should be attributed to the AHP criteria weights.

4) Looking more closely at the remaining cost surfaces that contributed to the accumulated cost surface, the extract by mask tool uncovers that the Proximity to Infrastructure and National Park categories are better suited LCP criteria. The other two criteria regarding Road Types and NLCD Land Cover classification indicate that the LCP is marginally better but still has room for improvement. Lastly, the LCP analysis is only as good as the quality of data procured for it. While the data used in the LCP analysis is accurate and reliable, further data collection and quality control would certainly enhance the analysis and results.

The results of the SFA analysis are displayed as choropleth maps in Figures 6-9. It has been recognized that no formal definition or measurement of accessibility exists within the literature presented in this study. Although, one can understand from this study how the use of network datasets and SFA information can come together to perform an assessment of the level of SFA one place has to another. Figure 6 displays the current state of SFA, determined by the level of effort it takes to drive to Las Vegas from any of the census tracts of Los Angeles County (the first scenario, Table 2). The pattern in Figure 6 suggests that the northern and eastern part of LA County has greater drive access to Las Vegas than the central, southern, and western part of the county due to the census tracts being closer to Las Vegas. Figure 7 and Figure 8 respectively display the future state of SFA with the anticipated construction of the LCP derived and VT's planned HSR corridor between Victorville and Las Vegas (the second and

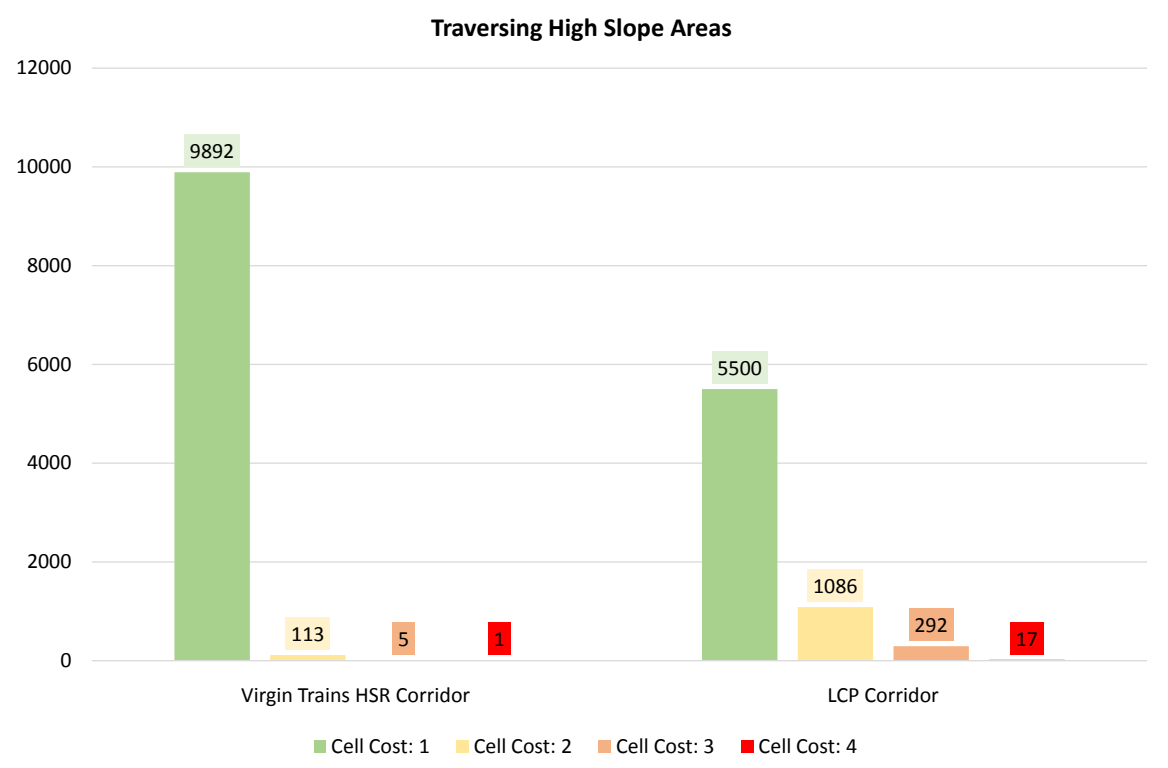

Figure 5. A cost criterion that VT's planned corridor is better suited. 


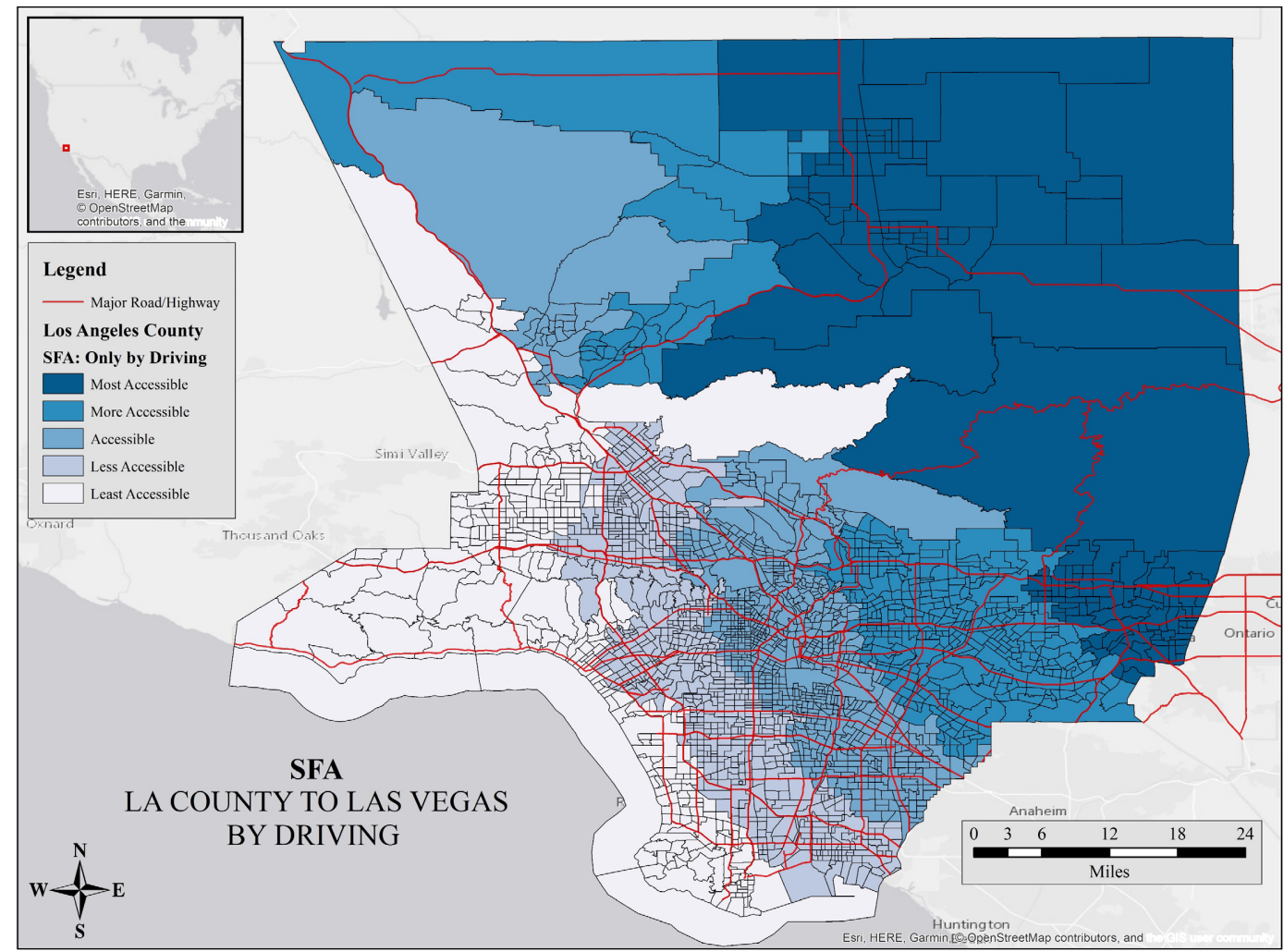

Figure 6. The system facilitated accessibility of LA County to Las Vegas by way of driving.

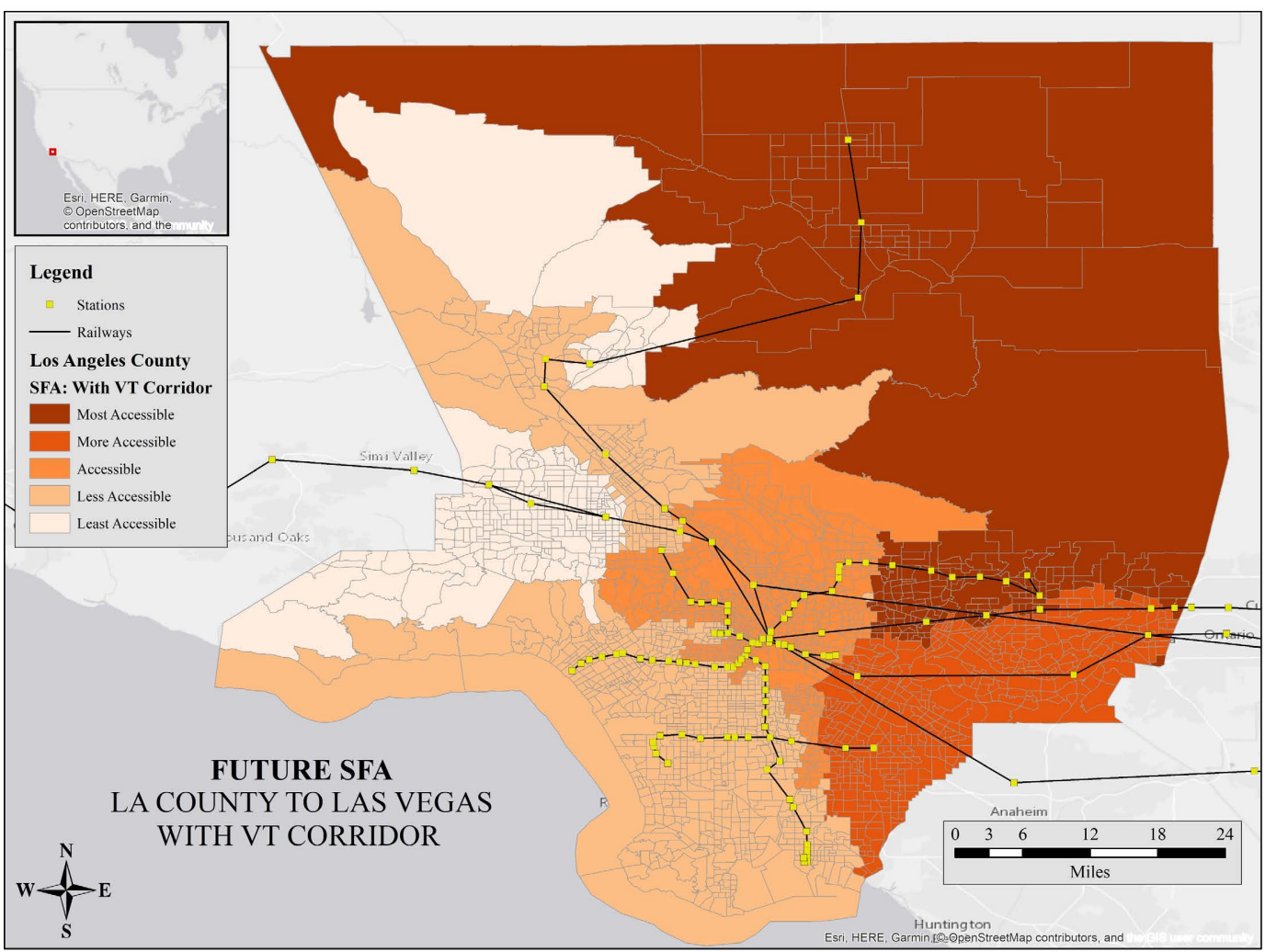

Figure 7. The system facilitated accessibility of LA County to Las Vegas by way of driving or taking the train with the inclusion of VT's planned HSR corridor. 


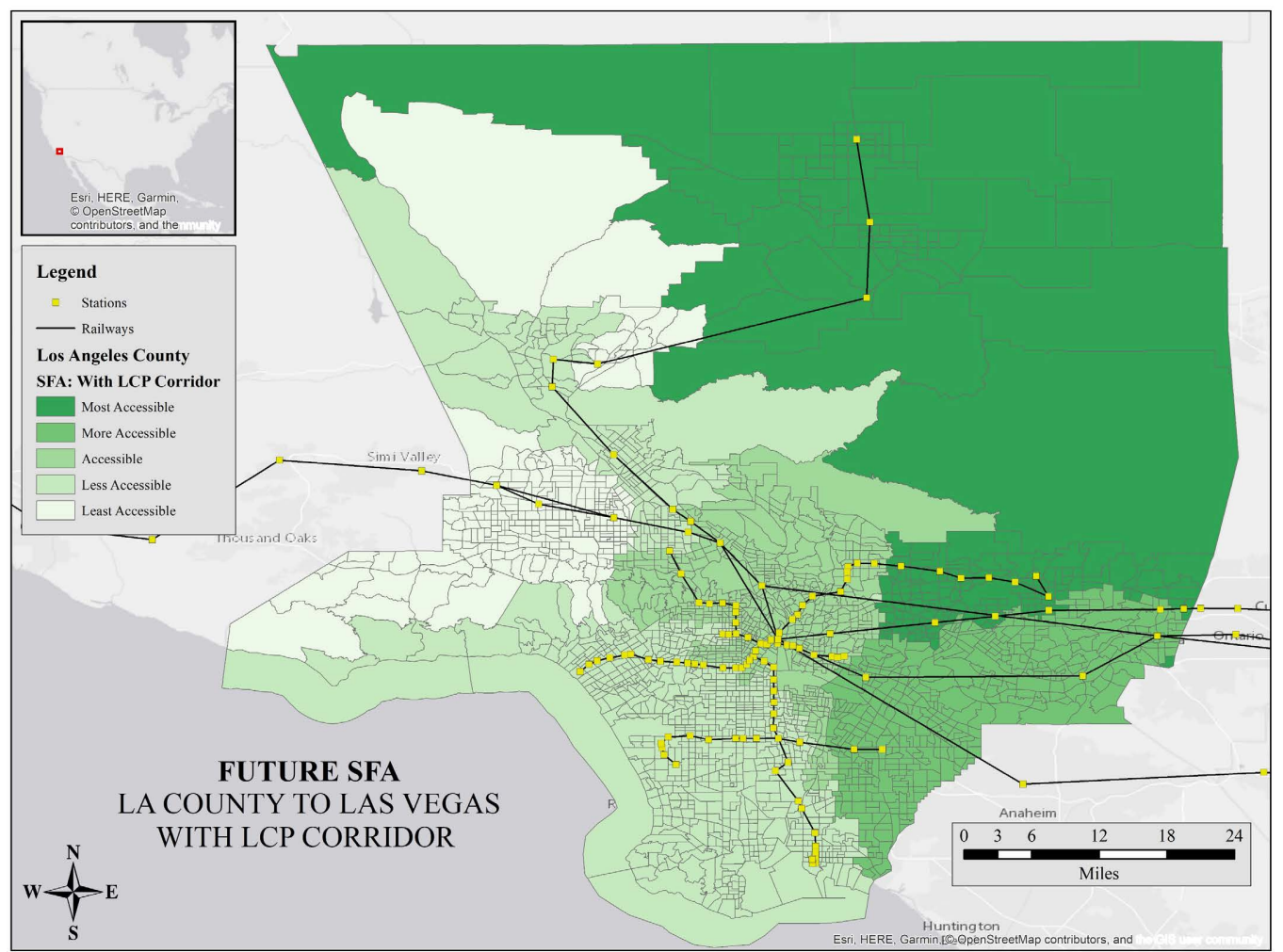

Figure 8. The system facilitated accessibility of LA County to Las Vegas by way of driving or taking the train with the inclusion of the proposed LCP alternative HSR corridor.

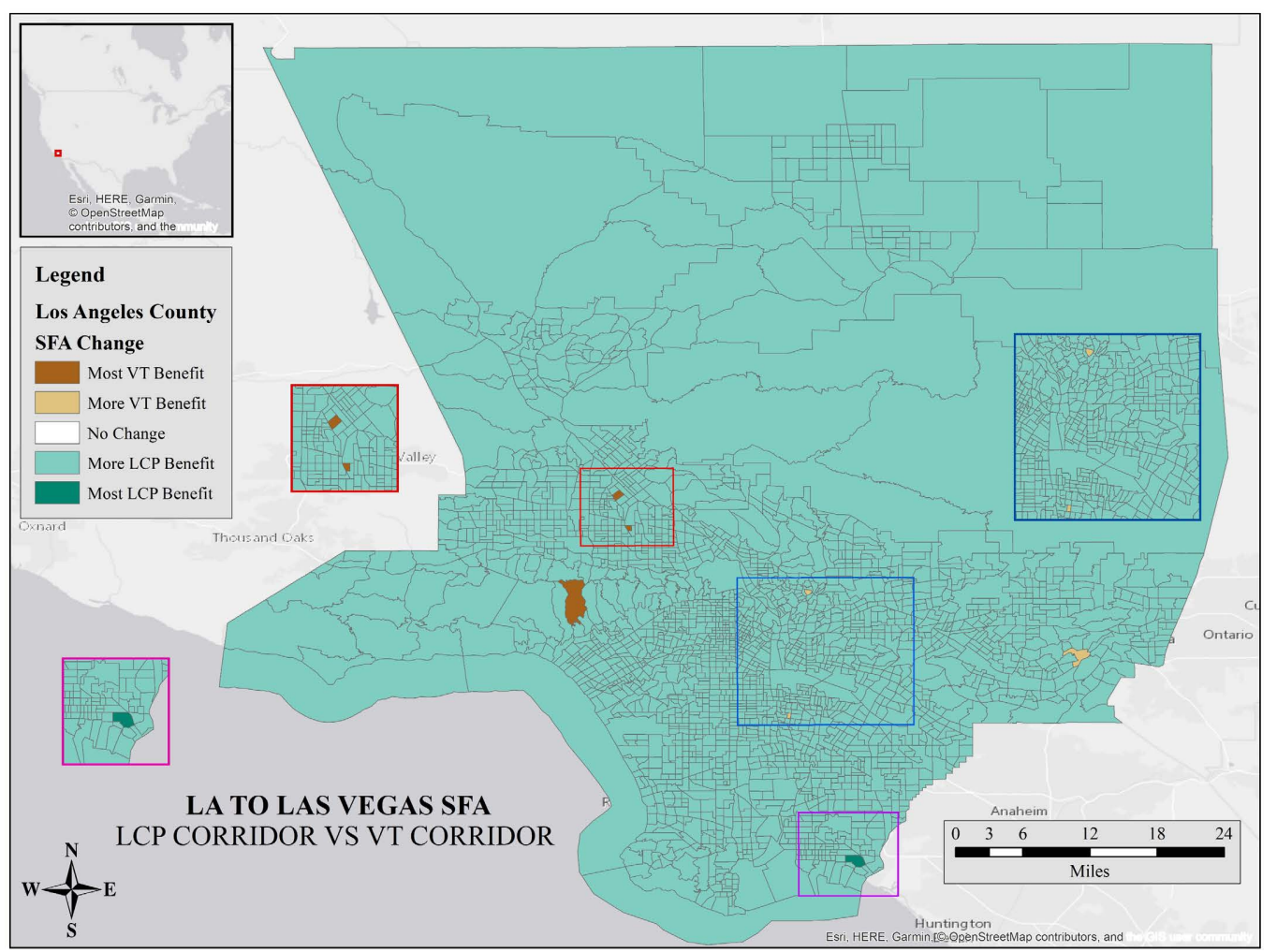

Figure 9. A visualization of the difference in social impact both the proposed LCP alternative and VT's planned HSR corridors provide LA County. 
third scenario, Table 2). The visual patterns in Figure 7 and Figure 8 suggest that the same difference in accessibility exists for LA County when comparing the northern, eastern, and central sections of LA County with the southern and western sections. However, Figure 9 displays the difference in SFA at a census tract level when considering Figure 7 compared to Figure 8. The second and third scenarios increase LA County's SFA to Las Vegas overall. But Figure 9 illustrates that only six LA County census tracts experienced a negative percent change in SFA. This indicates that while a new HSR corridor can be constructed and improve all of LA County's SFA to Las Vegas, less than 1\% (specifically $0.26 \%$ ) of census tracts are more accessible with VT's planned corridor to Las Vegas. $99.74 \%$ of LA County would experience better SFA with the proposed LCP-HSR corridor. Of the $99.74 \%$ of census tracts that are in favor of the proposed LCP-HSR corridor, an overwhelming $99.9 \%$ of them fall within a range of greater than $0 \%$ or less than or equal to $11.3 \%$ better off than the VT proposed corridor.

An additional four limitations focus on the network dataset constructed in this study to calculate SFA:

1) Within the network dataset, impedance attributes like "Speed" and "Fare" (train ticket cost) can be made more descriptive. Most importantly, there is only the assumption that the HSR fare VT will charge will be 10 USD. Any increase or decrease in that amount, or changes to the other network dataset elements' cost attributes will certainly alter this study's results.

2) No cost impedances exist for time constraints e.g., railway schedules, stop lights in traffic, as well as traffic itself. More sophisticated network datasets include one-way streets, live traffic data as well as wait-time penalties to accessibility when a user of the network must wait for a train to arrive. In this study, no such cost impedances or restrictions exist due to the absence of public information or lack of research on the authors' behalf.

3) The network dataset also assumes that a user of the network is a single person rather than a group of people where costs less train fares can be split in a car-pooling manner, possibly making driving to Las Vegas more accessible for some than others.

4) The equations used to determine system facilitated accessibility are simplified and less in-depth than those presented in [37]. This includes the absence of using cost as the impedance measure (rather than time) when solving routes in the network dataset.

In spite of these limitations, the major next steps to improve an analysis such as this could be:

1) Consult experts/stakeholders of VT HSR project and request their input into the AHP model for defining criteria weights.

2) Acquire a more exact location of VT HSR and its one-way ticket cost.

3) Incorporate a detailed network dataset to provide a more reliable and accurate assessment of system facilitated accessibility. 
4) Improve upon the equations used to determine system facilitated accessibility that account for value of time and coefficients of determination that afflict one's perception of accessibility versus the reality of it.

Until these improvements can be satisfied there is still a lot to learn from a LCP analysis for corridor selection. The study represents a combinational-influence of the past attempts at LCP creation and accessibility measuring referenced in the supporting literature. There exist many attempts to utilize GIS as a means to accomplish these objectives with or without taking responsibility for quantifiably evaluating the results. While results may look interesting or favorable on a map, one cannot be too sure of the outcome until the data is evaluated. Data-driven analysis facilitated by GIS is a popular method of operational research, but it is ultimately the diligent work of the software-users that justify the results.

\section{Conclusions}

This study employed ESRI's ArcMap to construct a LCP and create a SFA index to appraise each LA County census tract to contrast the change in SFA each tract experienced when a new HSR is operational between LA and Las Vegas. Based on the criteria provided in this study, the combined difference in the accumulated costs during LCP analysis and SFA shows the proposed LCP alternative HSR corridor is overall less costly and more accessible than the planned VT HSR corridor. Therefore, with the impacts to the stakeholders and users of the VT HSR project in mind, this study provided an optimized alternative LCP-HSR corridor and further analyzed the alternative LCP corridor against the VT planned corridor to determine which is least costly based on the criteria described above in Figure 2. In addition, this study extended the analysis to assess the social impact to the users by a SFA index. By completing this, the LCP has experienced a more robust analysis and created a foundation for predicting a good return on investment (ROI) for the stakeholders of the HSR project.

A proper method for justifying expensive transportation projects like VT's HSR project should be included in future research. The existing methods prior to this study do not extend far enough to justify transportation projects because they do not address the users of transportation systems. Basic LCP analysis presented in the literature sections of this study may be enough for other linear engineering projects like pipelines, telecommunication lines, or other projects that do not directly transport people. The current work presented in this study can be improved by incorporating more information that impacts the accessibility analysis, namely the network dataset construction that produced the accessibility results. Although, the LCP analysis has extended existing research to go beyond what has already been accomplished by including aspects of accessibility in justifying an optimized alternative with information and methods that VT could consider in the future.

\section{Conflicts of Interest}

The authors declare no conflicts of interest regarding the publication of this paper. 


\section{References}

[1] Martin, B. (2020) Dine Outdoors at the Virgin Trains Las Vegas Terminal in 2023. Eater: Las Vegas.

https://vegas.eater.com/2020/2/11/21132392/virgin-trains-las-vegas-terminal-openi ng-2023-dining-restaurants.

[2] Martella, M. (2020) Brightline: High Speed Rail to Vegas. GoNOMAD Travel. https://www.gonomad.com/156439-virgin-trains-high-speed-rail-to-vegas.

[3] Cathcart, S.C., Gomezdelcampo, E., Gorsevski, P.V., Jamali, M.M., Mirzaei, Golrokh, Steven, C. and Ye, X. (2013) A Group-Based Spatial Decision Support System for Wind Farm Site Selection in Northwest Ohio. Energy Policy, 55, 374-385. https://doi.org/10.1016/j.enpol.2012.12.013

[4] Saaty, R.W. (1987) The Analytic Hierarchy Process-What It Is and How It Is Used. Mathematical Modeling, 9, 161-176. https://doi.org/10.1016/0270-0255(87)90473-8

[5] Höfer, T., Madlener, R., Siddique, H. and Sunak, Y. (2016) Wind Farm Siting Using a Spatial Analytical Hierarchy Process Approach: A Case Study of the Städteregion Aachen. Applied Energy, 163, 222-243. https://doi.org/10.1016/j.apenergy.2015.10.138

[6] Júnior, O.L., Morgado, A.V. and Portugal, L. de Silva. (2011) Location of Cargo Terminals in Metropolitan Areas of Developing Countries: The Brazilian Case. Journal of Transport Geography, 19, 900-910. https://doi.org/10.1016/j.jtrangeo.2010.11.005

[7] Uyan, M. (2013) GIS-Based Solar Farms Site Selection Using Analytic Hierarchy Process (AHP) in Karapinar Region, Konya/Turkey. Renewable and Sustainable Energy Reviews, 28, 11-17. https://doi.org/10.1016/j.rser.2013.07.042

[8] Bediroglu, S. and Yildirim, V. (2019) A Geographical Information System-Based Model for Economical and Eco-Friendly High-Speed Railway Route Determination Using Analytical Hierarchy Process and Least-Cost Path Analysis. Expert Systems, 36, Article ID: e12376. https://doi.org/10.1111/exsy.12376

[9] Atkinson, D.M., Deadman, P., Dudycha, D. and Traynor, S. (2005) Multi-Criteria Evaluation and Least Cost Path Analysis for an Article All-Weather Road. Applied Geography, 25, 287-307. https://doi.org/10.1016/j.apgeog.2005.08.001

[10] Bagli, S., Geneletti, D. and Orsi, F. (2011) Routing of Power Lines through LeastCost Path Analysis and Multicriteria Evaluation to Minimise Environmental Impacts. Environmental Impact Assessment Review, 31, 234-239.

https://doi.org/10.1016/j.eiar.2010.10.003

[11] LaRue, M.A. and Nielsen, C.K. (2008) Modelling Potential Dispersal Corridors for Cougars in Midwestern North America Using Least-Cost Path Methods. Ecological Modelling, 212, 372-381. https://doi.org/10.1016/j.ecolmodel.2007.10.036

[12] Gao, C., Tang, Y. and Wu, X. (2020) Urban Ecological Corridor Network Construction: An Integration of the Least Cost Path Model and the Invest Model. ISPRS International Journal of Geo-Information, 9, Article No. 33.

https://doi.org/10.3390/ijgi9010033

[13] Krejčí, J. (2018) Pairwise Comparison Matrices and Their Fuzzy Extension: Multi-Criteria Decision Making with a New Fuzzy Approach. Vol. 366, Springer International Publishing, Cham. https://doi.org/10.1007/978-3-319-77715-3

[14] Lusby, R.M., Larsen, J. and Bull, S. (2018) A Survey on Robustness in Railway Planning. European Journal of Operational Research, 266, 1-15.

https://doi.org/10.1016/j.ejor.2017.07.044

[15] Liden, T. (2015) Railway Infrastructure Maintenance-A Survey of Planning Prob- 
lems and Conducted Research. Transportation Research Procedia, 10, 574-583. https://doi.org/10.1016/j.trpro.2015.09.011

[16] Kim, J. and Shin, N. (2021) Planning for Railway Station Network Sustainability Based on Node-Place Analysis of Local Stations. Sustainability, 13, Article No. 4778. https://doi.org/10.3390/su13094778

[17] Canca, D. and Barrena, E. (2018) The Integrated Rolling Stock Circulation and Depot Location Problem in Railway Rapid Transit Systems. Transportation Research Part E, 109, 115-138. https://doi.org/10.1016/j.tre.2017.10.018

[18] Zhang, C., Gao, Y., Yang, L., Kumar, U. and Gao, Z. (2019) Integrated Optimization of Train Scheduling and Maintenance Planning on High-Speed Railway Corridors. Omega, 87, 86-104. https://doi.org/10.1016/j.omega.2018.08.005

[19] Jin, G., He, S., Li, J., Li, Y., Guo, X. and Xu, H. (2019) An Integrated Model for Demand Forecasting and Train Stop Planning for High-Speed Rail. Symmetry, 11, Article No.720. https://doi.org/10.3390/sym11050720

[20] Yue, Y., Wang, S., Zhou, L., Tong, L. and Rapik Saat, M. (2016) Optimizing Train Stopping Patterns and Schedules for High-Speed Passenger Rail Corridors. Transportation Research, 63, 126-146. https://doi.org/10.1016/j.trc.2015.12.007

[21] U.S. Department of Transportation and Federal Railroad Administration (2009) Vision for High-Speed Rail in America. The American Recovery and Reinvestment Act.

[22] Guirao, B. and Campa, J.L. (2014) The Construction of a HSR Network Using a Ranking Methodology to Prioritize Corridors. Land Use Policy, 38, 290-299. https://doi.org/10.1016/j.landusepol.2013.11.017

[23] Jurkovic, Z., Hadzima-Nyarko, M. and Lovokovic, D. (2021) Railway Corridors in Croatian Cities as Factors of Sustainable Spatial and Cultural Development. Sustainability, 13, Article No. 6928. https://doi.org/10.3390/su13126928

[24] Xu, W., Long, Y. and Zhang, W. (2019) Prioritizing Future Funding and Construction of the Planned High-Speed Rail Corridors of China-According to Regional Structure and Urban Land Development Potential Indices. Transport Policy, 81, 381-395. https://doi.org/10.1016/j.tranpol.2017.08.002

[25] Chow, E., Lu, Y. and Medel, M. (2015) Mexico's Drug Networks: Modeling the Smuggling Routes towards the United States. Applied Geography, 60, 240-247. https://doi.org/10.1016/j.apgeog.2014.10.018

[26] Aydun, C.C., Durmaz, A.I. and Unal, E.O. (2019) Automatic Pipeline Route Design with Multi-Criteria Evaluation Based on Least-Cost Path Analysis and Line-Based Cartographic Simplification: A Case Study of the Mus Project in Turkey. ISPRS International Journal of Geo-Information, 8, Article No. 173. https://doi.org/10.3390/ijgi8040173

[27] Cruz-Chavez, M.A., Moreno-Bernal, P., Rivera-Lopez, R., Avila-Melgar, E.Y., Martinez-Bahena, B. and Cruz-Rosales, M.H. (2020) GIS Spatial Optimization for Corridor Alignment Using Simulated Annealing. Applied Sciences, 10, Article No. 6190. https://doi.org/10.3390/app10186190

[28] Choi, Y., Park, H., Sunwoo, C. and Clarke, K.C. (2008) Multi-Criteria Evaluation and Least-Cost Path Analysis for Optimal Haulage Routing of Dump Trucks in Large Scale Open-Pit Mines. International Journal of Geographical Information Science, 23, 1541-1567. https://doi.org/10.1080/13658810802385245

[29] Hong, I. and Murray, A.T. (2016) Assessing Raster GIS Approximation for Euclidean Shortest Path Routing. Transactions in GIS, 20, 570-584. 
https://doi.org/10.1111/tgis.12160

[30] Kim, H., Wunneburger, D. and Neuman, M. (2013) High-Speed Rail Route and Regional Mobility with a Raster-Based Decision Support System: The Texas Urban Triangle Case. Journal of Geographic Information Systems, 5, 559-566. https://doi.org/10.4236/jgis.2013.56053

[31] Kumagai, T.G. and Wachs, M. (1973) Physical Accessibility as a Social Indicator. Socio-Economic Planning Sciences, 7, 437-456. https://doi.org/10.1016/0038-0121(73)90041-4

[32] Cheah, J.T.S., Heng, B.H., Tan, C.B. and Wong, L.Y. (2012) Using Spatial Accessibility to Identify Polyclinic Service Gaps and Volume of Under-Served Population in Singapore Using Geographic Information System. The International Journal of Health Planning and Management, 27, e173-e185. https://doi.org/10.1002/hpm.1063

[33] Penchansky, R. and Thomas, J.W. (1981) The Concept of Access: Definition and Relationship to Consumer Satisfaction. Medical Care, 19, 127-140. https://doi.org/10.1097/00005650-198102000-00001

[34] Hägerstrand, T. (1970) What about People in Regional Science? Papers of the Regional Science Association, 24, 6-21. https://doi.org/10.1007/BF01936872

[35] Church, R.L. and Lei, T.L. (2010) Mapping Transit-Based Access: Integrating GIS Routes and Schedules. International Journal of Geographical Information Science, 24, 283-304. https://doi.org/10.1080/13658810902835404

[36] Church, R.L. and Marston, J.R. (2003) Measuring Accessibility for People with a Disability. Geographical Analysis, 35, 83-96. https://doi.org/10.1111/j.1538-4632.2003.tb01102.x

[37] Barr, S.L., Dawson, R.J., Ford, A.C. and James, P. (2015) Transport Accessibility Analysis Using GIS: Assessing Sustainable Transport in London. ISPRS International Journal of Geo-Information, 4, 124-149. https://doi.org/10.3390/ijgi4010124

[38] McKenzie, B. (2015) Who Drives to Work? Commuting by Automobile in the United States: 2013. United States Census Bureau, Suitland. https://www.census.gov/library/publications/2015/acs/acs-32.html

[39] United States Census Bureau (2019) TIGER/Line Shapefiles. [tl_2019_06037_roads.shp, tl_2019_06071_roads.shp, and tl_2019_32003_roads.shp]. https://www.census.gov/geographies/mapping-files/time-series/geo/tiger-line-file.html

[40] Mcdonald, M. (2020) CapstoneRepo [Source Code]. https://github.com/maxxxswell/capstoneRepo.git 